International Journal of Automotive and Mechanical Engineering ISSN: 2229-8649 (Print); ISSN: 2180-1606 (Online);

Volume 14, Issue 1 pp. 3812-3823 March 2017

CUniversiti Malaysia Pahang Publishing

DOI: https://doi.org/10.15282/ijame.14.1.2017.1.0311

\title{
Effect of tensile strain rates on flow stress for extruded AZ31 and AZ61 magnesium alloys
}

\author{
N. Abdul Latif ${ }^{1 *}$, Z. Sajuri ${ }^{2}$ and J. Syarif ${ }^{3}$ \\ ${ }^{1}$ Faculty of Mechanical and Manufacturing Engineering, \\ Universiti Tun Hussein Onn Malaysia, 86400 Parit Raja, Johor, Malaysia \\ Email: noradila@uthm.edu.my \\ Phone: +60126371171; Fax: +6074536080 \\ ${ }^{2}$ Faculty of Engineering and Built Environment, Universiti Kebangsaan Malaysia, \\ 43600 UKM Bangi, Selangor, Malaysia \\ ${ }^{3}$ Mechanical Engineering Department, College of Engineering, University of Sharjah, \\ PO Box: 27272, Sharjah, UAE
}

\begin{abstract}
Aluminium-Zinc (AZ) is a popular series of magnesium alloy and is used in automobile components and structures. In this regard, the AZ series is subject to high velocity and impact loads during accidents. Thus, it is essential that the effect of tensile strain rates i.e., low and intermediate strain rates, on flow stress of extruded AZ31 and AZ61 magnesium alloys is investigated. In this study, tensile test under low strain rates were fixed at $1 \times 10^{-4}, 1 \times 10^{-3}, 1 \times 10^{-2}$ and $1 \times 10^{-1} \mathrm{~s}^{-1}$, while tensile tests under intermediate strain rates were fixed at 100, 200, 400 and $600 \mathrm{~s}^{-1}$. The tensile test specimens were prepared with a gage length and diameter of $10 \mathrm{~mm}$ and $3 \mathrm{~mm}$, respectively. Flow stress was determined by averaging the values of yield stress and tensile strength of the alloy. The results showed that the flow stresses of both extruded magnesium alloys were strain rate dependent. This is believed to be due to the increasing dislocation density in the materials. Thus, the resistance to deformation increased with an increasing volume of dislocation density for extruded AZ31 and AZ61 alloys. Moreover, the flow stresses of both alloys were strain rate dependent; the activation of critical resolved shear stress (CRSS) of non-basal slip systems for magnesium alloys significantly influenced the deformation mechanism of the materials. Additionally, flow stresses of both magnesium alloys increased at increasing strain rate due to the large numbers of twinning in alloys. Hence, tensile strain rates significantly affect the flow stress and failure mechanism of magnesium alloys.
\end{abstract}

Keywords: Flow stress; low and intermediate strain rates; dislocation density; CRSS; twinning; extruded magnesium alloys.

\section{INTRODUCTION}

Aluminium-Zinc (AZ) magnesium alloys are beneficial in automobile applications for preventing or reducing the impact of critical damage in cases of accidents due to its ductile property. The good ductility of AZ magnesium alloys allows them to be easily produced in the shape of extruded products for automotive applications . Moreover, extruded magnesium products have better dynamic strength compared to cast magnesium products [1]. Sajuri et al. [2] reported that the tensile properties of extruded AZ61 alloy was higher than that of as-cast AZ61 alloy. In automotive applications, 
structural components made from magnesium alloys are constantly subject to high velocity during accidents. Thus, examining the mechanical properties of these alloys is essential to determining their behaviour under high strain rates and loads.

Tensile properties are commonly determined under low strain rates, which are less than $0.01 \mathrm{~s}^{-1}$ at room temperature. Meanwhile, high strain rate tensile properties are acquired by tensile tests at high strain rates or dynamic response. A high strain rate (also known as the impact loading rate or dynamic loading rate) is generally associated with high impact and acceleration. High strain rates typically range from 100 to $1 \times 10^{4} \mathrm{~s}^{-1}$. In this test condition, a Split Hopkinson pressure bar tester (also known as Kolsky apparatus) is used to conduct the tensile test at high strain rate up to $1 \times 10^{4} \mathrm{~s}^{-1}$ [3]. The high strain rate tensile test of a drop weight event is used to perform the test at strain rates below $1 \times 10^{3} \mathrm{~s}^{-1}$, which rely on the drop weight height of the tester. The strain rate range of the drop weight impact tester is also known as the intermediate or moderate strain rate [4-6]. Hasenpouth et al. [4] studied the effect of intermediate strain rate for an AZ31B magnesium alloy sheet, while Kong et al. [5] studied both mild and stainless steels. They found that at increasing strain rates, tensile properties are strain rate dependent. For magnesium alloys, Abdullah et al. [7] reported that these alloys were capable of withstanding high speed impacts that performed using the Split Hopkinson pressure bar tester. However, the trend of tensile properties at low to intermediate strain rates for extruded AZ31 and AZ61 magnesium alloys are still unknown. In this study, the effects of low and intermediate strain rates on flow stress for extruded AZ31 and AZ61 magnesium alloys were investigated.

\section{METHODS AND MATERIALS}

Two types of as-received extruded magnesium alloys, AZ31 and AZ61, were used in this study. For these two alloys, the chemical compositions are listed in Table 1 and microstructures are shown in Figure 1. Obviously, aluminium content in AZ61 was higher than in AZ31, which influences the microstructure of alloys. Thus, the AZ31 had larger grain size compared to AZ61 with the average grain sizes of the AZ31 and AZ61 were $24.4 \mu \mathrm{m}$ and $15.0 \mu \mathrm{m}$, respectively. The numbers of twinning for AZ31 were also found to be higher compared to AZ61. The Vickers hardness test was carried out for extruded AZ31 and AZ61 magnesium alloys. It was found that the average Vickers hardness of AZ31 and AZ61 magnesium alloys were 57.3 HV and 60.6 HV respectively as shown in Figure 2.
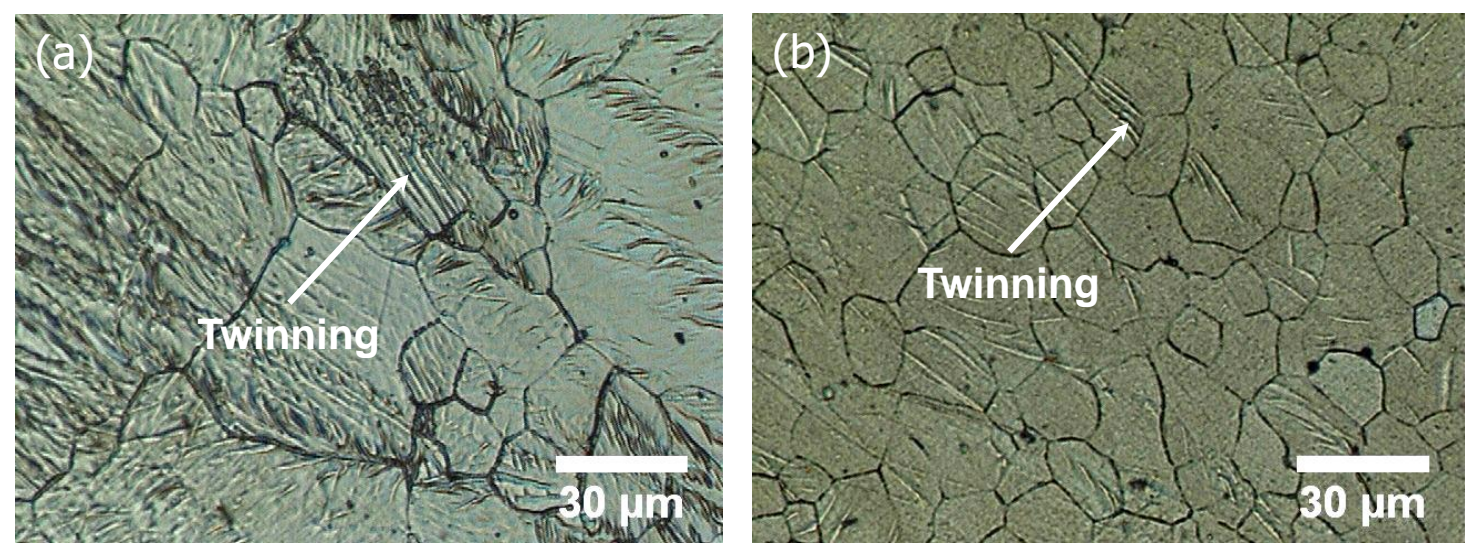

Figure 1. Microstructures of extruded (a) AZ31 and (b) AZ61 magnesium alloys. 
Table 1. Chemical compositions of extruded AZ31 and AZ61 magnesium alloys.

\begin{tabular}{lllllllll}
\hline & $\mathrm{Al}$ & $\mathrm{Zn}$ & $\mathrm{Mn}$ & $\mathrm{Fe}$ & $\mathrm{Si}$ & $\mathrm{Cu}$ & $\mathrm{Ni}$ & $\mathrm{Mg}$ \\
\hline $\mathrm{AZ31}$ & 3.35 & 0.88 & 0.33 & 0.003 & 0.01 & $<0.002$ & $<0.002$ & Balance \\
$\mathrm{AZ61}$ & 5.84 & 0.65 & 0.29 & 0.002 & 0.01 & 0.001 & 0.0003 & Balance \\
\hline
\end{tabular}

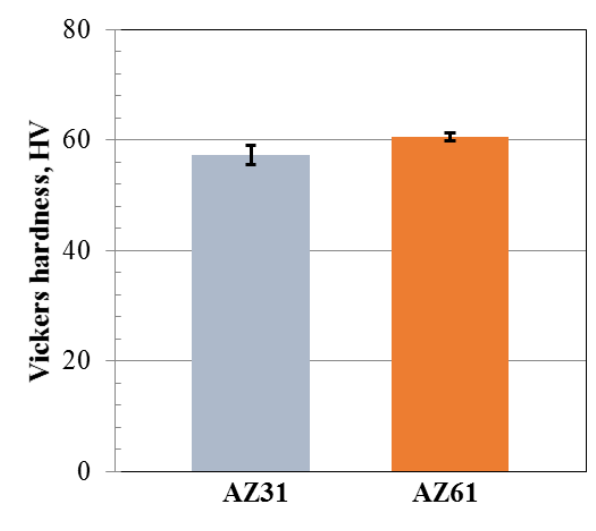

Figure 2. Hardness of extruded AZ31 and AZ61 magnesium alloys.

The American Society for Testing and Materials, ASTM E8M [8] was referred to perform the tensile test for extruded magnesium alloys. Tensile tests were conducted under low and intermediate strain rates using two different tensile test machines. For low strain rates, the tensile test was carried out using a universal testing machine (UTM) with a load cell capacity of $100 \mathrm{kN}$ under strain rates of $1 \times 10^{-4}, 1 \times 10^{-3}, 1 \times 10^{-2}$ and 1 $\times 10^{-1} \mathrm{~s}^{-1}$. Meanwhile, the tensile test under intermediate strain rate was performed using the high strain rate tensile tester with a load cell capacity of $125 \mathrm{kN}$ under strain rates of 100, 200, 400 and $600 \mathrm{~s}^{-1}$. The high strain rate tensile tester (as shown in Figure 3) was designed and fabricated cause limit the strain rate by the UTM, where it was only operated up to a maximum strain rate of $0.5 \mathrm{~s}^{-1}$. The high strain rate tensile tester was developed based on the free fall principle with a drop weight event. Detailed geometries and dimensions of the round tensile test specimens, for low and intermediate strain rate tensile tests, are shown in Figure 4. Tensile properties were obtained from the tensile test. Flow stress was subsequently determined from the average of the yield stress and tensile strength of the magnesium alloys.

\section{Design of High Strain Rate Tensile Tester}

Several important parameters for the high strain rate tensile tester were included, such as tensile test configuration, measurement device, recording data system, safety parts and height of drop weight for producing a dynamic response. This tester was designed and fabricated in-house to perform the tensile test under intermediate strain rates that ranged between 100 and $600 \mathrm{~s}^{-1}$. The minimum and maximum heights of the drop weight were approximately 0.05 and $2 \mathrm{~m}$, respectively. The development of the high strain rate tensile tester sought to perform the tensile test under intermediate strain rates using the free fall weight principle using the influence of gravity acceleration. This refers to the conservation of energy equation, within which, the potential energy before the tensile test is identical to the kinetic energy after the tensile test. This refers to Equation (1). 


$$
m g h=\frac{1}{2} m v^{2}
$$

where $m$ is the mass, $g$ the acceleration of gravity $\left(9.81 \mathrm{~m} / \mathrm{s}^{2}\right), h$ the drop weight height and $v$ the impact velocity or strain rate.

The mass of the drop weight used in the high strain rate tensile tester was $25 \mathrm{~kg}$ (the weight of the drop weight was $245.3 \mathrm{~N}$ ). The drop weight was used to produce an intermediate strain rate, after release, at the desired tensile test height. The tensile test specimen would subsequently experience an impact tensile response, just after the drop weight hits the impact platform. Hence, the tensile test intermediate strain rate was significantly dependent on the drop weight height.

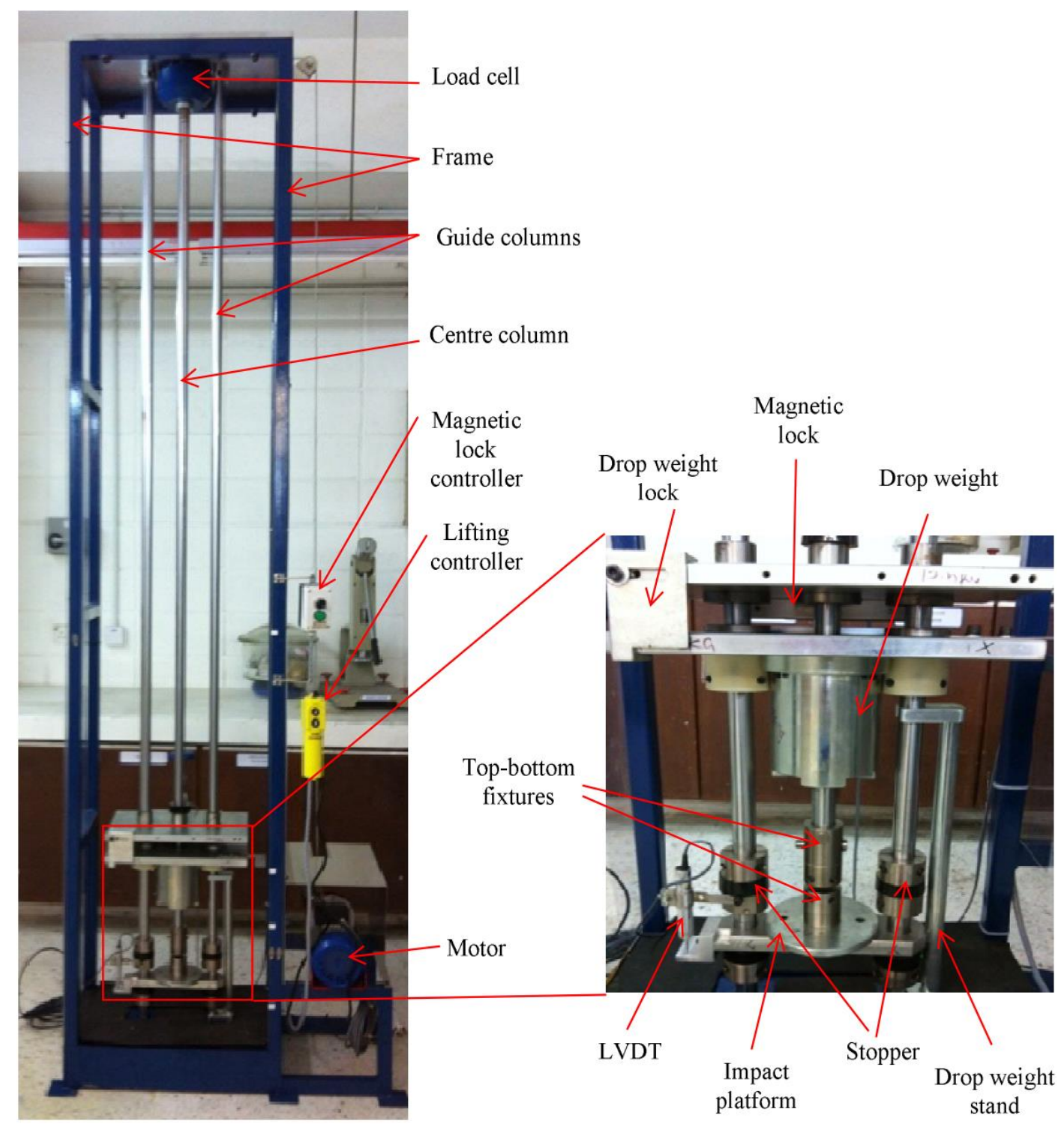

Figure 3. High strain rate tensile tester.

Prior to carrying out the tensile test under intermediate strain rate, two calibration tests were performed to ensure the capability of the high strain rate tensile tester to record the correct data of the experiment. The load cell is calibrated by adding 
weight. Figure 5 shows the calibration curve of the load measured by the load cell against different weights. The load was proportional to increasing weight. Comparing the calibration curve (solid line) and actual curve (dotted line), it was found that the percentage of error was $3.6 \%$. This means that a small error would occur during testing, and this was considered acceptable.

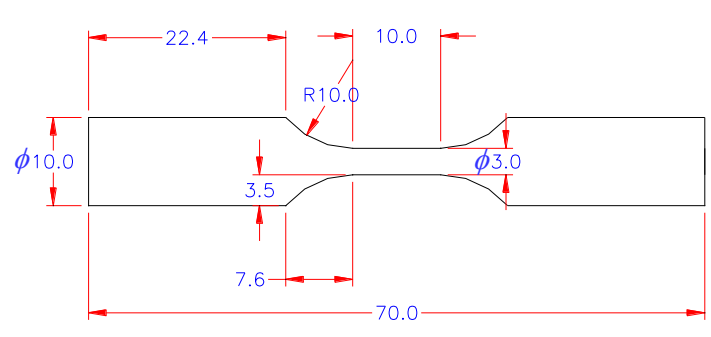

(a)

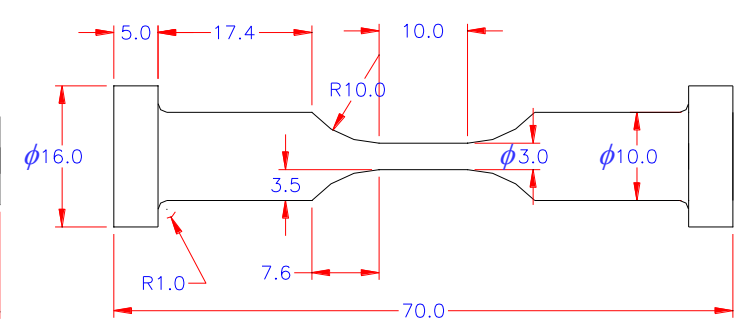

(b)

Figure 4. Tensile test specimens for (a) low and (b) intermediate strain rate tensile tests.

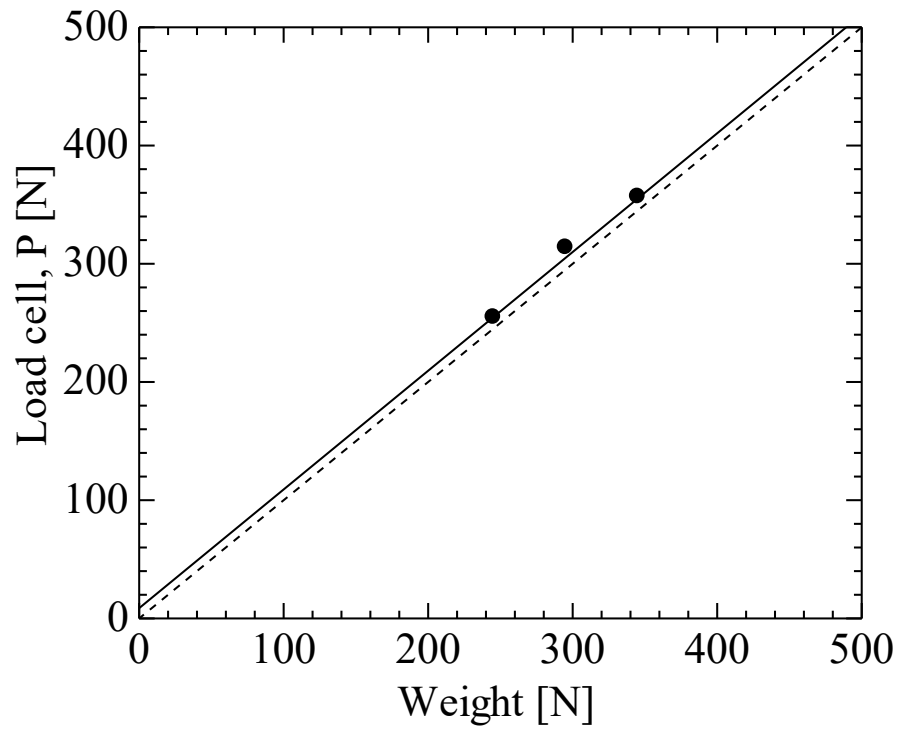

Figure 5. Calibration curve of load cell against different weights.

Afterwards, a calibration test of strain rate against the drop weight height was conducted to compare the actual strain rate and calculated strain rate of the free fall body equation. Timer and proximity sensors were used to record the moving time of the drop weight at distances of proximity sensors prior to hitting the impact platform. The distance of two proximity sensors was fixed at $139 \mathrm{~mm}$. The recorded moving time and the distance of two proximity sensors were used to evaluate the actual strain rate, which is the distance between two proximity sensors divided to the recorded moving time and gage length of the specimen. Figure 6 shows the calibration curve of the calculated and actual strain rates under different drop weight heights. This curve indicates that both strain rates increase with an increase in drop weight height. The calculated strain rate was evaluated using Equation (2) based on the free fall principle without considering any sliding friction. Equation (2) was simplified from the conservation of energy equation as in Equation (1). The actual strain rate is calculated by considering the small 
sliding friction between the drop weight and smooth guide columns. However, the actual strain rate is found to be slightly lower than the calculated strain rate due to the sliding friction effect between the drop weight and smooth guide columns.

$$
v=\sqrt{2 g h}
$$

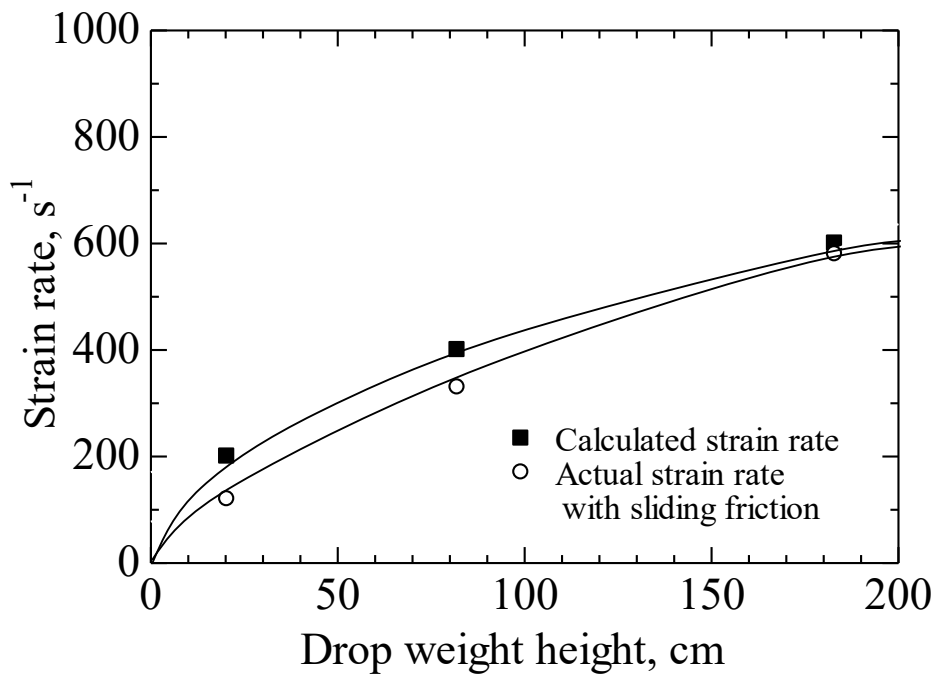

Figure 6. Calibration curve of strain rate under different drop weight heights.

\section{RESULTS AND DISCUSSION}

The effects of low and intermediate strain rates on the tensile properties of extruded AZ31 and AZ61 magnesium alloys are listed in Table 2. The flow stress of AZ61 was higher than that of AZ31 at all strain rates. This is believed to be due to the large amount of aluminium content in the alloy [9]. High aluminium content in AZ61 significantly decreased the grain size and presence of precipitation where it tends to cause more dislocation piled up due to blocking at large grain boundaries [10-12] and precipitation [13]. Figure 7 contains the flow stresses of both alloys and shows a slight increment in the strain rate range of $1 \times 10^{-4}$ to $100 \mathrm{~s}^{-1}$. However, above 200 to $600 \mathrm{~s}^{-1}$, the flow stresses increase dramatically by three to four times compared to those at low strain rates. Takuda et al. [14] reported that flow stress increases at high strain rate due to the increasing dislocation density for the $\mathrm{Mg}-8.5 \mathrm{Li}-1 \mathrm{Zn}$ alloy. Similarly, for the ZK60 magnesium alloy, Li et al. [15] reported that the dislocation density increases at high strain rates. It was found that the resistance to deformation increases with an increasing volume of dislocation density [16]. For the aluminium 7071 alloy, Bobbili et al. [17] also reported that the tensile flow stress increases with increasing strain rates as the high strain rate provides shorter time to energy accumulation, which thus increases the stress level. However, the flow stresses of extruded AZ31 and AZ61 are significantly higher at strain rates above 200 to $600 \mathrm{~s}^{-1}$ compared to those at high strain rates reported by Li et al. (2009) for ZK60 magnesium alloy and Bobbili et al. [17] for the aluminium 7071 alloy. Furthermore, the flow stresses of both extruded magnesium alloys are strain rate dependent, whereby the activation of critical resolved shear stress (CRSS) of non-basal slip systems for magnesium alloys significantly influenced the deformation mechanism of the alloys [18, 19]. Meanwhile, the flow stresses at low 
strain rates were mainly governed by the activation of CRSS of the basal slip plane of magnesium alloys [19, 20]. In addition, Li et al. [15] and Trojanová et al. [21] reported that twinning increases by increasing the strain rate for magnesium alloys as it also contributes to higher flow stress. Twinning provides a high dislocation slip by producing more barriers between grains [22]. Moreover, Koike et al. [23], Barnett [24, 25] and Yasutomi and Enoki [26] argued that twinning formation results in extruded materials from the extrusion process.

Figure 8 shows the effect of strain rate on elongations of extruded AZ31 and AZ61 magnesium alloys. Elongation is strain rate dependent as it decreases at increasing strain rate for both magnesium alloys. This is due to the shorter time needed to deform at high strain rates. Furthermore, elongation decreases are caused by the dislocation movement or slip deformation which cannot keep up at high strain rate [27]. In previous studies, Mukai et al. [28] also reported that the elongation to fracture of ZK60 decreases at high strain rates. Feng et al. [27] explained that the reduction of plasticity for AZ31B at high strain rates is caused by the limited time to plastic deformation; hence, the elongation is reduced at high strain rates.

Table 2. Effect of low and intermediate strain rates on tensile properties for extruded AZ31 and AZ61 magnesium alloys.

\begin{tabular}{cccccc}
\hline $\begin{array}{c}\text { Strain rate } \\
{\left[\mathrm{s}^{-1}\right]}\end{array}$ & $\begin{array}{c}\text { Yield stress } \\
{[\mathrm{MPa}]}\end{array}$ & $\begin{array}{c}\text { Tensile strength } \\
{[\mathrm{MPa}]}\end{array}$ & $\begin{array}{c}\text { Flow stress } \\
{[\mathrm{MPa}]}\end{array}$ & $\begin{array}{c}\text { Elongation at fracture } \\
{[\%]}\end{array}$ \\
\hline $1 \times 10^{-4}$ & 173 & 226 & 200 & 15.7 \\
$1 \times 10^{-3}$ & 191 & 240 & 216 & 16.2 \\
$1 \times 10^{-2}$ & 217 & 249 & 233 & 14.4 \\
$\mathrm{AZ31}$ & 204 & 251 & 228 & 15.4 \\
\cline { 2 - 5 } $1 \times 10^{-1}$ & 100 & 214 & 260 & 237 & 13.2 \\
200 & 662 & 990 & 826 & 14.8 \\
400 & 687 & 1007 & 847 & 12.2 \\
$\mathrm{AZ61}$ & 744 & 1063 & 903 & 14.3 \\
\hline $1 \times 10^{-1}$ & 221 & 316 & 261 & 16.2 \\
$1 \times 10^{-4}$ & 205 & 327 & 273 & 16.6 \\
$1 \times 10^{-2}$ & 219 & 317 & 273 & 12.0 \\
100 & 273 & 335 & 270 & 14.4 \\
\hline 400 & 806 & 1039 & 304 & 10.0 \\
600 & 759 & 1111 & 922 & 13.4 \\
& 809 & 1077 & 935 & 10.3 \\
\hline
\end{tabular}

Figures 9 and 10 show the effects of high strain rate on the tensile fracture surface of AZ31 and AZ61 magnesium alloys, respectively. The fractographs of AZ31 and AZ61 magnesium alloys differ due to the different microstructure of both alloys caused by the effect of aluminium content. The AZ61 alloy certainly has a ductile fracture pattern in comparison to the AZ31 alloy due to the presence of large numbers of dimples on the fracture surface. Nevertheless, AZ31 still indicated a ductile fracture pattern. Referring to the fracture surface tested at a strain rate of $600 \mathrm{~s}^{-1}$, the fracture surface of AZ31 indicated more cleavage fractures and steps, while AZ61 indicated that fewer dimples were formed. These two fracture behaviours were different when compared to the fracture surface of the specimen tested at a strain rate of $100 \mathrm{~s}^{-1}$. 
Similarly, Lin and Chen [16] reported that cleavage-like fracture appears at fracture surfaces of specimens tested at high strain rates, while at low strain rates, dimple-like ductile fractures are observed for AZ31B. This means that the ductility of AZ31 and AZ61 magnesium alloys slightly decrease with increasing strain rate.

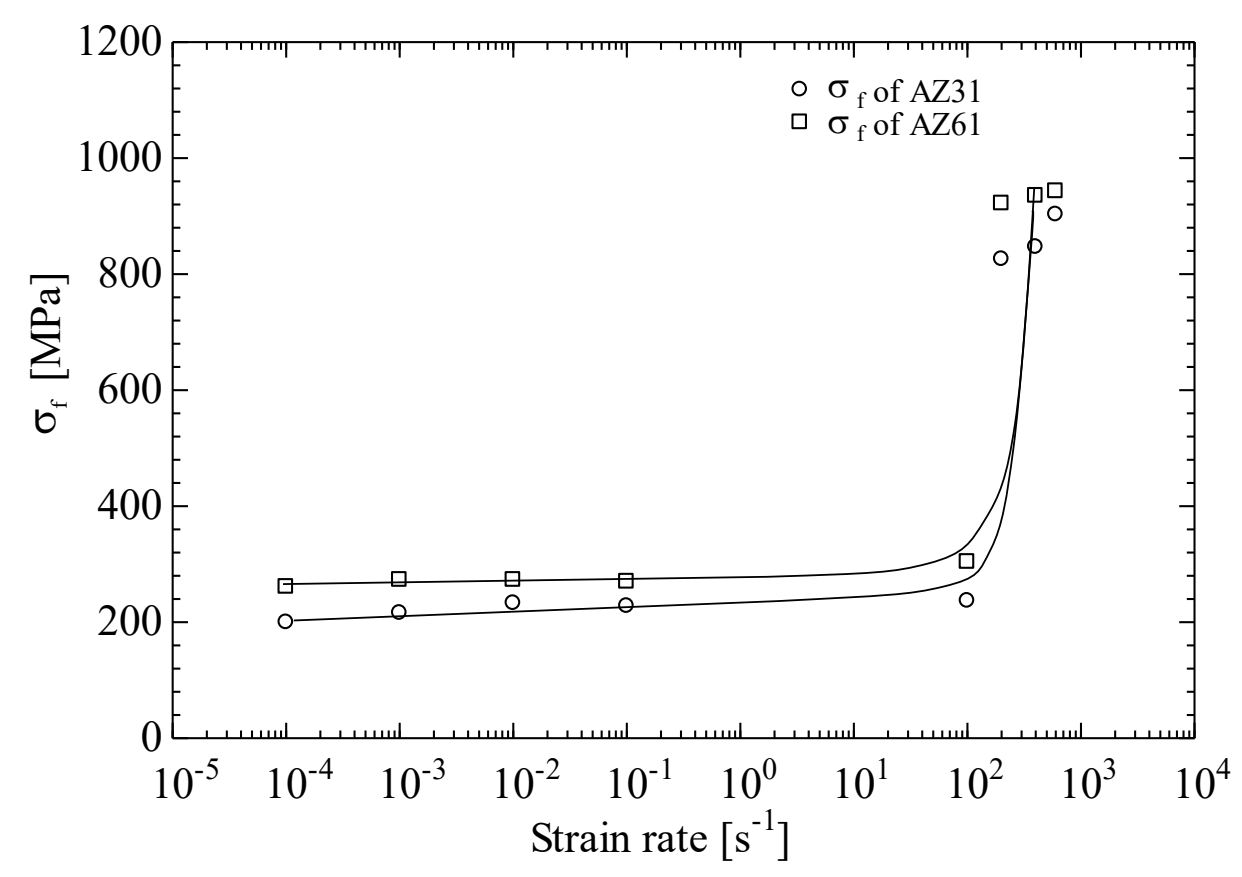

Figure 7. Effect of strain rate on flow stresses for extruded AZ31 and AZ61 magnesium alloys.

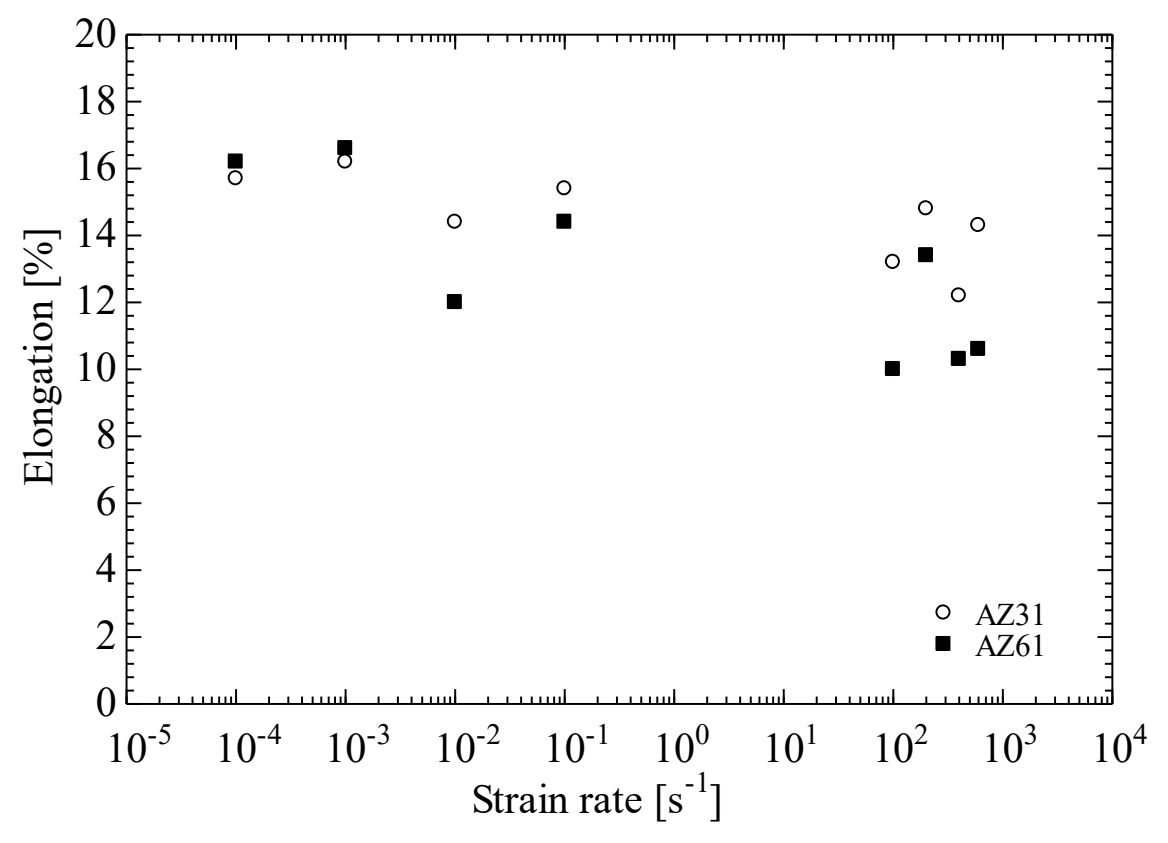

Figure 8. Effect of strain rate on elongations for extruded AZ31 and AZ61 magnesium alloys. 

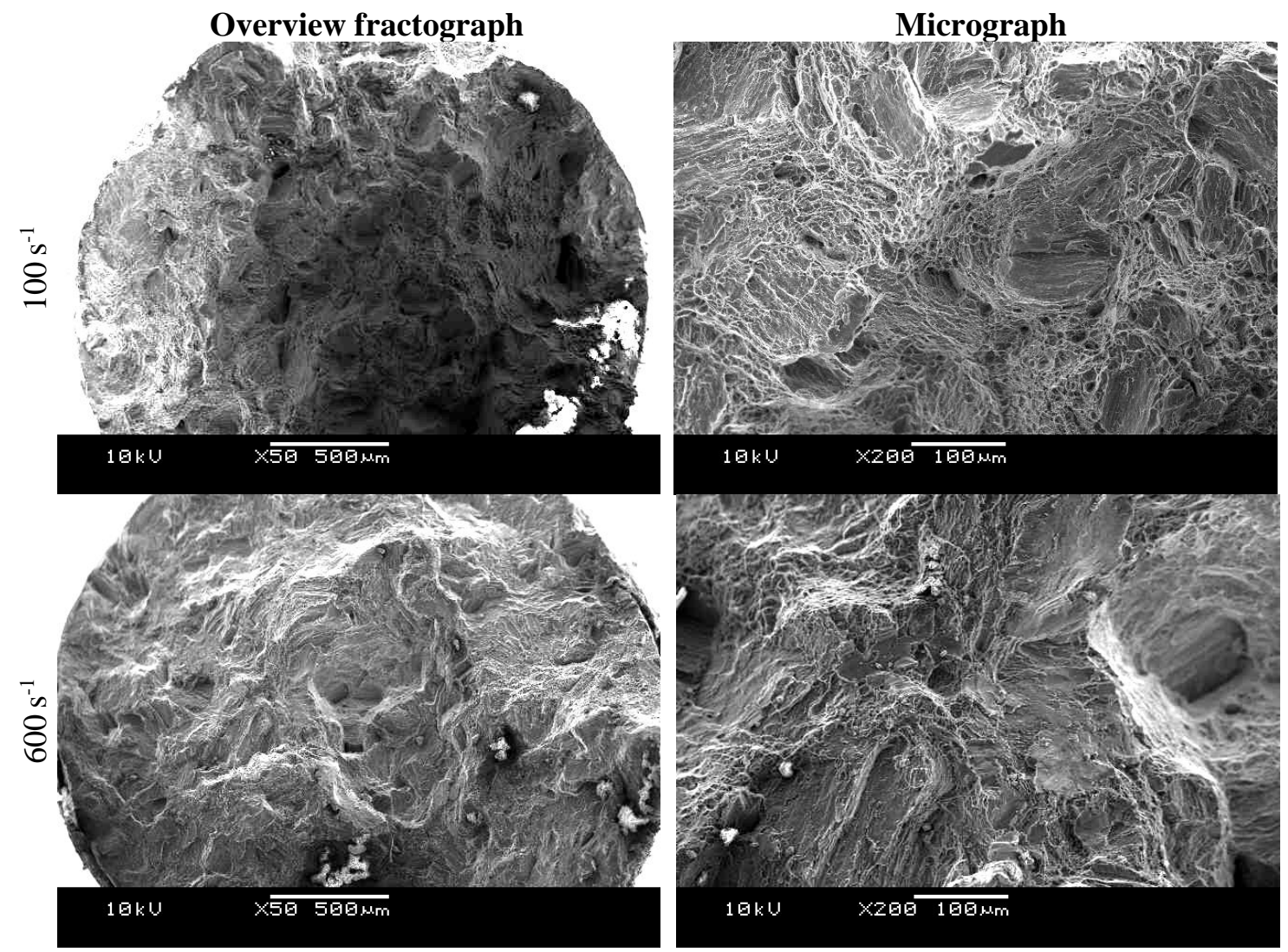

Figure 9. Fractograph showing the effect of intermediate strain rate on AZ31.
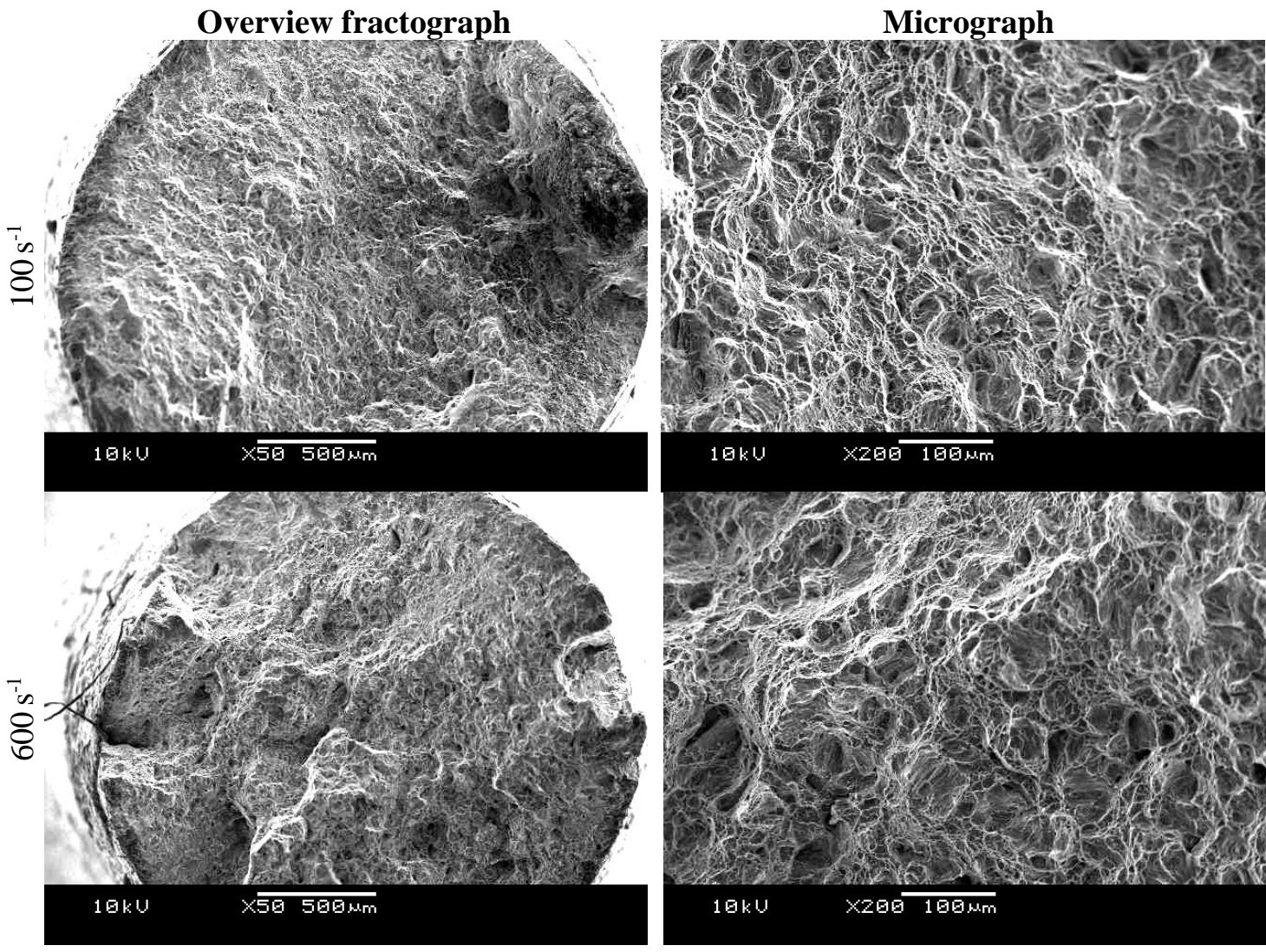

Figure 10. Fractograph showing the effect of intermediate strain rate on AZ61. 


\section{CONCLUSIONS}

Tensile tests under low and intermediate strain rates for extruded AZ31 and AZ61 magnesium alloys were carried out. Based on the results obtained, it was found that the flow stress of these two magnesium alloys were strain rate dependent. It is suggested that the flow stress of AZ31 and AZ61 magnesium alloys increased at increasing strain rates due to high dislocation density and the activation of critical resolved shear stress (CRSS) of non-basal slip systems for magnesium alloys. Twinning also increased by increasing the strain rate. Thus, the flow stresses of these two alloys increased. High twinning corresponded to higher induced dislocation density, which makes slip deformation difficult in alloys. It was found that elongations at the fracture of both magnesium alloys slightly decreased with increasing strain rate. Furthermore, the flow stress of the AZ61 alloy was higher compared to that of the AZ31 alloy at all strain rates. The hardness of the AZ61 alloy was also higher than that of the AZ31 alloy. A high aluminium content in the AZ61 magnesium alloy significantly increased the flow stress and hardness of this alloy. This was due to the high aluminium content in magnesium alloys contributing to a reduction in grain size, increment of grain boundary, presence of precipitation and twinning in microstructure. In the fractograph, the AZ61 alloy significantly fractured in a ductile pattern due to the large numbers of dimples on the fracture surface. Thus, it is beneficial for preventing sudden fractures.

\section{ACKNOWLEDGEMENTS}

The authors acknowledge the supports from the Universiti Kebangsaan Malaysia, Ministry of Higher Education Malaysia (FRGS/1/2013/TK01/UKM/02/4), Nagaoka University of Technology and Universiti Tun Hussein Onn Malaysia.

\section{REFERENCES}

[1] Becker J, Fischer G. Manufacturing and potential of extruded and forged magnesium products. Magnesium-Alloys and Technology. 2004:90-105.

[2] Sajuri ZB, Miyashita Y, Hosokai Y, Mutoh Y. Effects of mn content and texture on fatigue properties of as-cast and extruded az61 magnesium alloys. International Journal of Mechanical Sciences. 2006;48:198-209.

[3] Davis JR. Tensile testing: ASM international; 2004.

[4] Hasenpouth D, Salisbury C, Bardelcik A, Worswick M. Constitutive behavior of magnesium alloy sheet at high strain rates. Proceedings of DYMAT 2009 9th International Conference on the Mechanical and Physical Behavior of Materials under Dynamic Loading, Brussels, Belgium; 2009.

[5] Kong SY, Remennikov AM, Uy B. The effect of medium strain rates on the mechanical properties of high performance steels. Proceedings of the $21 \mathrm{st}$ Australasian Conference on the Mechanics of Structures and Materials, held in Melbourne, Australia; 2011. p. 685-90.

[6] Zabotkin K, O'Toole B, Trabia M. Identification of the dynamic tensile properties of metals under moderate strain rates. 16th ASCE Engineering Mechanics Conference, University of Washington, Seattle; 2003.

[7] Abdullah M, Abdullah S, Rahman N, Risby M, Omar M, Sajuri Z. Improvement of high velocity impact performance of carbon nanotube and lead reinforced 
magnesium alloy. International Journal of Automotive and Mechanical Engineering. 2016;13:3423-33.

[8] ASTM E8-04. Standard test methods for tension testing of metallic materials. Annual book of ASTM Standards ASTM; 2004.

[9] Chamos A, Pantelakis SG, Haidemenopoulos G, Kamoutsi E. Tensile and fatigue behaviour of wrought magnesium alloys az31 and az61. Fatigue \& Fracture of Engineering Materials \& Structures. 2008;31:812-21.

[10] Kapoor R, Singh J, Chakravartty J. High strain rate behavior of ultrafine-grained al-1.5 mg. Materials Science and Engineering: A. 2008;496:308-15.

[11] Kim H, Chang Y. Deformation mechanism temperature-dependence of az31 magnesium alloy. Metals and Materials International. 2011;17:563-8.

[12] Catorceno LLC, Lopes DA. Annealing of cold and warm rolled az31b magnesium alloy sheets. Magnesium Technology 2013. p. 133-7.

[13] Tański T. Synergy effect of heat and surface treatment on properties of the mgal-zn cast alloys. Journal of Achievements in Materials and Manufacturing Engineering. 2012;54:260--74.

[14] Takuda H, Kikuchi S, Kubota K. Formability and strain rate sensitivity of a mg-8.5 li-1zn alloy sheet. Magnesium Alloys and their Applications. 2000:28590.

[15] Li B, Joshi S, Azevedo K, Ma E, Ramesh K, Figueiredo R, et al. Dynamic testing at high strain rates of an ultrafine-grained magnesium alloy processed by ecap. Materials Science and Engineering: A. 2009;517:24-9.

[16] Lin X, Chen D. Strain hardening and strain-rate sensitivity of an extruded magnesium alloy. Journal of Materials Engineering and Performance. 2008; 17:894.

[17] Bobbili R, Madhu V, Gogia AK. Tensile behaviour of aluminium 7017 alloy at various temperatures and strain rates. Journal of Materials Research and Technology. 2016;5:190-7.

[18] Ulacia I, Dudamell N, Gálvez F, Yi S, Pérez-Prado M, Hurtado I. Mechanical behavior and microstructural evolution of a $\mathrm{mg}$ az31 sheet at dynamic strain rates. Acta Materialia. 2010;58:2988-98.

[19] Kurukuri S, Bardelcik A, Worswick M, Mishra R, Carter J. High strain rate characterization of zek100 magnesium rolled alloy sheet. EPJ Web of Conferences: EDP Sciences; 2012. p. 01042.

[20] Styczynski A, Hartig C, Bohlen J, Letzig D. Cold rolling textures in az31 wrought magnesium alloy. Scripta Materialia. 2004;50:943-7.

[21] Trojanová Z, Lukáč P, Podrábský T, Pešička J. High strain rate behaviour of an az31+ 0.5 ca magnesium alloy. Materials Engineering-Materiálové Inžinierstvo (MEMI). 2011;19:12-7.

[22] Yablinsky CA, Cerreta EK, Gray GT, Brown DW, Vogel SC. The effect of twinning on the work-hardening behavior and microstructural evolution of hafnium. Metallurgical and Materials Transactions A. 2006;37:1907-15.

[23] Koike J, Kobayashi T, Mukai T, Watanabe H, Suzuki M, Maruyama K, et al. The activity of non-basal slip systems and dynamic recovery at room temperature in fine-grained az31b magnesium alloys. Acta Materialia. 2003;51:2055-65.

[24] Barnett MR. Twinning and the ductility of magnesium alloys. Part i: "Tension" twins. Materials Science and Engineering A. 2007;464:1-7. 
[25] Barnett MR. Twinning and the ductility of magnesium alloys part ii. "Contraction" twins. Materials Science and Engineering A. 2007;464.

[26] Yasutomi T, Enoki M. In-situ evaluation of detwinning behavior in extruded az31 mg alloy by ae. Materials Transactions. 2012;53:1611-6.

[27] Feng F, Huang S, Meng Z, Hu J, Lei Y, Zhou M, et al. Experimental study on tensile property of az $31 \mathrm{~b}$ magnesium alloy at different high strain rates and temperatures. Materials \& Design. 2014;57:10-20.

[28] Mukai T, Watanabe H, Ishikawa K, Higashi K. Guide for enhancement of room temperature ductility in mg alloys at high strain rates. Materials Science Forum; 2003. p. 171-6. 